Original Article

\title{
SULFASALAZINE ATTENUATES ULCERATIVE COLITIS IN RATS VIA DOWNREGULATION OF MIRNA-31, METALLOPROTEINASE-3 AND HIGH MOBILITY GROUP BOX1
}

\author{
SYLVIA A. BOSHRA \\ Biochemistry Department, Faculty of Pharmacy, October 6 University, Giza, Egypt \\ Email: sylviaazmy@yahoo.com
}

Received: 11 Apr 2021, Revised and Accepted: 07 Jun 2021

\begin{abstract}
ABSTACT
Objective: This study targets the inhibition of inflammatory mediators and the enhancement of gastrointestinal mucosa healing in ulcerative colitis in rats through sulfasalazine.

Methods: Twenty four female albino rats were divided into 3 groups: normal control, colitis group (rats received 5\% dextran sodium sulfate (DSS) in their drinking water for $7 \mathrm{~d}$ ), sulfasalazine group $(500 \mathrm{mg} / \mathrm{kg} /$ day was administrated orally one week ahead of DSS and parallel with its administration). The impact of sulfasalazine on intestinal inflammation was investigated via estimation of some inflammatory mediators, namely; serum Leucine rich $\alpha 2$ Glycoprotein (LRG) as well as colon cAMP, Myloperoxidase (MPO) and TNF- $\alpha$ using ELISA technique as well as gene expression of Trefoil Factor 3 (TFF3), High mobility group box1 (HMGB1), Nuclear factor kappa B (NF- $\mathrm{kB}$ ) and metalloproteinase-3 (MMP3) and miRNA-31 levels using RT-PCR.
\end{abstract}

Results: Sulfasalazine substantially decreases the release of LRG, MPO and TNF- $\alpha$ and the expression of HMGB1, NF- $\kappa B$, MMP3, TFF3 and miRNA31 at $p \leq$ 0.05 compared to colitis group in vivo. Moreover, Sulfasalazine significantly increases the colonic cAMP at $p \leq 0.05$ in groups of rats treated with DSS.

Conclusion: Sulfasalazine has a protective effect on inflammatory bowel disease causing mucosal healing within the gastrointestinal tract. Additional studies are warranted to explore the molecular mechanism of sulfasalazine in ulcerative colitis and its clinical application.

Keywords: Dextran sodium sulfate, Leucine rich $\alpha 2$ Glycoprotein, Trefoil Factor 3, Nuclear factor kappa B

(c) 2021 The Authors. Published by Innovare Academic Sciences Pvt Ltd. This is an open access article under the CC BY license (https://creativecommons.org/licenses/by/4.0/) DOI: https://dx.doi.org/10.22159/ijpps.2021v13i8.41775. Journal homepage: https://innovareacademics.in/journals/index.php/ijpps.

\section{INTRODUCTION}

Inflammatory bowel disease (IBD) comprises Crohn's disease (CD) and ulcerative colitis (UC) is thought to be triggered by an irregular immune response resulting in a genetically prone host malfunction of the intestinal mucosal barrier against enteric bacteria [1]. The UC is based on the abnormal degradation of the intestinal mucosa due to various reasons; including genetic, environmental, microbial and immune inflammatory mediators [2]. The treatment priorities for IBDs include complication prevention, recovery and rehabilitation of nutritional deficiencies to improve the quality of life of patients. In the treatment of IBDs, the anti-inflammatory drugs include immunosuppressants, biological agents, antibiotics, and drugs to quash inflammatory responses and to alleviate symptoms [3]. A great number of cytokine abnormalities, including proinflammatory and immunoregulatory molecules have been described. In $\mathrm{CD}$, interferongamma (INF) $\gamma \gamma$ is generated by intestinal CD4+T cells, while interleukin 12 and 18 are released by mucosal macrophages [3].

The most commonly used mouse models of colitis utilize dextran sodium sulfate (DSS), a chemical colitogen with anticoagulant properties, for disease induction. Due to its speed, reproducibility, usability, and management, the DSS colitis model is very popular in IBD research. Acute, chronic and relapsing models of intestinal inflammation can be accomplished by altering DSS concentration and administration [4]

Sulfasalazine, which consists of 5-aminosalicylate (5-ASA-active component) and sulfapyridine, demonstrated its induction efficacy and remission maintaining in mild to moderate UC [5]. Topical 5ASA is a member of distal disease [5]. ASA agents can have several anti-inflammatory effects, including inhibition of cyclooxygenase, lipoxygenase, B-cells and other inflammatory cytokines. 5-ASA has been shown to trigger the selective peroxisome proliferatorsactivated receptor ligand- $\gamma$ (PPAR- $\gamma$ ) which regulates cell proliferation and apoptosis [6]. It usually takes between 3 and $6 \mathrm{w}$ for induction of remission in mild to moderately active UC [7]. So, the present research was therefore carried out to determine the pharmacological effects of sulfasalazine and the molecular mechanisms underlying these effects through measuring genetic expression of Trefoil Factor 3 (TFF3), High mobility group box1 (HMGB1), Nuclear factor kappa B (NF-kB), Metalloproteinase-3 (MMP3) and miRNA31 levels and some inflammatory mediators in DSS-caused ulcerative colitis experimentally in rats.

\section{MATERIALS AND METHODS}

\section{Chemicals}

DSS (molecular weight: 36,000-50,000 Daltons), Sulfasalazine (purity $\geq$ 98\%), hexadecyltrimethylammonium bromide (HTAB), 0-dianisidine hydrochloride and potassium phosphate buffer were bought from Sigma Aldrich (St. Louis, MO, USA). The remaining chemicals used in this study were of the analytical grade, maintained under standard conditions, and supplied by standard commercial providers.

\section{Animals}

This experiment was performed in conjunction with guidelines laid down by the Animal Care using ethical Committee, approval no 20191120, Faculty of applied medical sciences, October 6 university. Adult female albino Wister rats weighing around $160 \pm 20 \mathrm{~g}$ were obtained from the Faculty of Veterinary Medicine, Cairo University (Cairo, Egypt). They were individually held in cages in an airconditioned room with a temperature of $23 \pm 2{ }^{\circ} \mathrm{C}, 60 \%$ relative humidity, and an 8:00 a. m. to 8:00 p. m. light cycle. Every animal was reared on a normal diet (Dyets, Inc., Bethlehem, PA, USA) ad libitum during the acclimatization period,

\section{Experimental setup}

This experiment was performed to investigate Sulfasalazine's protective effects against DSS-mediated ulcerative colitis in rats, and all the studied parameters have been repeated twice to ensure the reproducibility of the results. The animals were grouped into three, including eight animals each. 
Group I: Normal control (was given $0.5 \mathrm{ml}$ of autoclaved drinking water)

Group II: was treated with DSS, $5.0 \%$ in autoclaved drinking water for $7 \mathrm{~d}[8]$.

Group III: was given sulfasalazine orally $(500 \mathrm{mg} / \mathrm{kg}$ ) in autoclaved drinking water in a single daily dosage for $7 \mathrm{~d}$ before induction of $\mathrm{UC}$ and $7 \mathrm{~d}$ parallel with DSS [9].

On the $15^{\text {th }} d$, all rats were sacrificed, at the completion of the study, blood was obtained and serum was freshly used to estimate LRG as well as Real time quantitative PCR (RT-qPCR) for TFF3, HMGB1, NF$\kappa \mathrm{B}$ and MMP3.

The colon was subsequently excised and cleaned with ice-cold physiological saline from blood. Then, the tissue was dried between filter papers to absorb moisture. Colon tissues were homogenized in $45 \mathrm{mmol}$ potassium phosphate buffer $(\mathrm{pH} 6)$ solution that comprises $0.5 \%$ hexadecyltrimethylammonium bromide (HTAB). The colon homogenates were exposed to 3 freezing/thawing cycles, sonication for 30 seconds and centrifugation at $20,000 \times \mathrm{g}$ for $20 \mathrm{~min}$ at $4{ }^{\circ} \mathrm{C}$ [10]. O-dianisidine hydrochloride $0.167 \mathrm{mg} / \mathrm{ml}$ and $0.3 \% \mathrm{H}_{2} \mathrm{O}_{2}$ in 45 mmol potassium phosphate buffer $(\mathrm{pH}$ 6.0) were applied to the supernatant. ELISA kit was obtained from Glory science Co., Ltd. (China) and used to assess the levels of TNF- $\alpha$, cyclic AMP and MPO activity in colon tissue homogenate.

\section{Biochemical assays}

The serum level of LRG was quantitatively estimated by ELISA using the Rat LRG Assay Kit-IBL, Code No. 27770.

Colon TNF- $\alpha$ and cyclic AMP as well as myeloperoxidase (MPO, E. C. 1.11.2.2) activity were quantitatively estimated by ELISA according to Kawakami et al. [11], El-Ashmawy et al. [12] and Krawisz et al. [13] respectively. Finally, the protein content of liver tissue was calculated [14].

\section{miRNA-31 analysis using RT-qPCR}

Total RNA was extracted from myocardial tissue of rats from each group using Trizol reagent (Invitrogen, California, USA). The ultraviolet Spectrophotometer measured the concentration of extracted RNA (Agilent Technologies, CA, USA) and a gel imaging system analyzed the integrity of RNA (Bio-Rad Laboratories, Inc., Hercules, CA, USA). Stemloop real-time RT-PCR was used to determine the expression of miRNA31 [15]. The primers were as follows:

Forward, GTCGTATCCAGTGCAGGGTCCGAGGTATTCGCACTGGATACGACAGCTA $\mathrm{T}-3^{\prime}$

\section{Reverse, 5'-GCCGCAGGCAAGATGCTGGC- 3 '.}

The $25 \mu$ PCR reaction mixture consists of $1 \times$ SYBR premix Ex Taq mix (Takara), $2 \mu \mathrm{l}$ RT products and $10 \mathrm{nM}$ of both forward and reverse primer. Reactions were held on a 96-well plate at 95 ${ }^{\circ} \mathrm{C}$ for $30 \mathrm{sec}$, followed by 45 cycles of $95^{\circ} \mathrm{C}$ for $15 \mathrm{sec}$ and $60{ }^{\circ} \mathrm{C}$ for $21 \mathrm{sec}$. Dissociation from 65 to $95{ }^{\circ} \mathrm{C}$ was conducted to confirm the specificity of the amplification products. The threshold cycle data were determined using second derivative max settings. U6 was used as an internal control to standardize target miRNA levels. The primers of stem loop RT and amplification primers of U6 were defined by Ribobio Co., Ltd., Guangzhou, China).

\section{Reverse transcription quantitative PCR (RT-qPCR)}

Total RNA has been isolated using a Qiagen extraction kit (Qiagen, USA) as stated by instructions of manufacture.

\section{cDNA synthesis}

The total RNA $(0.5-2 \mu \mathrm{g})$ was used for cDNA conversion using high ability cDNA reverse transcription kit Fermentas, USA).

\section{Procedure}

Three $\mu \mathrm{l}$ of random primers were introduced to the $10 \mu \mathrm{l}$ of RNA that was denatured for $5 \mathrm{~min}$ at $65{ }^{\circ} \mathrm{C}$ in the thermal cycler, the mixture of RNA primer was refrigerated to $4{ }^{\circ} \mathrm{C}$ and the master mix of cDNA was prepared as outlined in the kit instructions and was applied to each sample (table 1):

Table 1: The cDNA master mix

\begin{tabular}{ll}
\hline Component & Volume \\
\hline First strand buffer & $5 \mu \mathrm{l}$ \\
10 mmoldNTPs & $2 \mu \mathrm{l}$ \\
RNase inhibitor $[40 \mathrm{U} / \mu \mathrm{l}]$ & $1 \mu \mathrm{l}$ \\
MMLV-RT enzyme $[50 \mathrm{U} / \mu \mathrm{l}]$ & $1 \mu \mathrm{l}$ \\
DEPC-treated water & $10 \mu \mathrm{l}$ \\
\hline
\end{tabular}

The total volume of the master mix was $19 \mu$ for each specimen. This was transferred to the $31 \mu \mathrm{l}$ RNA-primer mixture which results in $50 \mu \mathrm{l}$ of cDNA.

c) The last mixture was incubated in the programmed thermal cycler for one hour at $37^{\circ} \mathrm{C}$ followed by deactivation of enzymes at $95{ }^{\circ} \mathrm{C}$ for $10 \mathrm{~min}$, and finally cooled at $4{ }^{\circ} \mathrm{C}$. Then, RNA was turned into cDNA. The converted cDNA was held at $-20^{\circ} \mathrm{C}$.

\section{Real-time qPCR using SYBR green I}

Real-time qPCR amplification and analysis were carried out using an Applied Biosystem with software version 3.1 (StepOne ${ }^{\text {TM }}$, USA). The qPCR assay and the primer sets (table 2) were optimized at the annealing temperature.

Table 2: The primer sequence of the studied gene

\begin{tabular}{ll}
\hline Trefoil factor & Forward primer: 5'-TAATGCTGTTGGTGGTCCTG-3' \\
3 (TFF3) & Reverse primer: 5'-CAGCCACGGTTGTTACACTG-3' \\
HMGB1 & Forward: 5'-GCCTCGCGGAGGAAAATC-3' \\
& Reverse: 5'-AAGTTTGCACAAAGAATGCATATGA-3' \\
NF-Kb & Forward: 5'-GTGGAGGCATGTTCGGTAGTG-3' \\
& Reverse: 5'-TCTTGGCACAATCTTTAGGGC-3' \\
MMP3 & Forward: 5'-ACTCTACCACTCAGCCCAAGG-3' \\
& Reverse: 5' -TCCAGAGAGTTAGACTTGGTGG-3' \\
Beta actin & Forward 5'-ATCACCATCTTCCAGGAGCG-3' \\
& Reverse 5'-CCTGCTTCACCACCTTCTTG-3' \\
\hline
\end{tabular}

\section{Preparation of the reaction master mix for Q-PCR}

1-For every sample, the following reagents and volumes were applied:

Forward primer $1 \mu \mathrm{l}$, Reverse Primer $1 \mu \mathrm{l}$, Syber green mix $12.5 \mu \mathrm{l}$, cDNA template $5 \mu \mathrm{l}$, RNAse free water $5.5 \mu \mathrm{l}$.

\section{2-Running conditions for RT-PCR were as follows}

The cDNA was subjected to real-time PCR under the following conditions: $50{ }^{\circ} \mathrm{C}(2 \mathrm{~min})$ (one cycle), $95^{\circ} \mathrm{C}(15 \mathrm{sec}), 60{ }^{\circ} \mathrm{C}(1 \mathrm{~min})$, and $72^{\circ} \mathrm{C}(1 \mathrm{~min})(40$ cycles $)$

Calculation of Relative Quantification (RQ) (relative expression)

The relative quantitation was calculated due to Applied Bio system software utilizing the following equation

$\Delta \mathrm{Ct}=\mathrm{Ct}$ gene test $-\mathrm{Ct}$ endogenous control

$\Delta \Delta \mathrm{Ct}=\Delta \mathrm{Ct}$ sample1- $\Delta \mathrm{Ct}$ calibrator

$\mathrm{RQ}=$ Relative quantification $=2^{-\Delta \Delta \mathrm{Ct}}$

The $\mathrm{RQ}$ is the fold change compared to the calibrator (untreated sample)

\section{Histopathological examination}

Colon segments were fixed for $24 \mathrm{~h}$ in formalin, washed and dehydrated using serial alcohol dilution. The Specimen was washed in xylene, coated in paraffin wax and tissue blocks were cut at a 
thickness of $4 \mathrm{~mm}$ using microtome (Leica RM2155, Germany). The tissue parts obtained were placed on glass slides, deparaffinized, stained with hematoxylin and eosin (HandE) and checked with a light microscope. All histopathological processing of specimens was performed by a trained researcher oblivious to the identity of the specimen being examined to prevent any prejudice.

\section{Statistical analysis}

All the data were statistically evaluated by SPSS/15 software Hypothesis testing approaches included one-way analysis of variance (ANOVA) followed by the least significant difference (LSD) test. It was assumed that $\mathrm{p}$ values less than 0.05 would suggest statistical significance. All the findings were manifested as mean $\pm S D$ for eight separate determinations.

\section{RESULTS}

Acute inflammation occurred in the rats with DSS, including signs of body weight loss, loose feces/watery diarrhea and fecal blood presence; all of these signs intensified at $7 \mathrm{~d}$.

\section{Serum LRG and colonic MPO, TNF- $\alpha$ and cAMP}

DSS $5 \%$ significantly $(P<0.01)$ increased the levels of serum leucinerich alpha-2-glycoprotein (LRG) as well as colon MPO and TNF- $\alpha$ relative to the control group. Treatment with sulfasalazine $(500$ $\mathrm{mg} / \mathrm{kg}$ ) for $7 \mathrm{~d}$ before UC induction and parallel with DSS, showed significant $(\mathrm{P}<0.05)$ inhibition in level of LRG, MPO and TNF- $\alpha$ as compared with the DSS group (table 3). The colonic cAMP level was significantly $(\mathrm{P}<0.01)$ reduced in DSS administered group as compared with control animals. Treatment with sulfasalazine significantly elevated the level of colonic cAMP level $(\mathrm{P}<0.05)$ as compared with the DSS group (table 3).

\section{Genetic expression levels of TTF3, HMGB1, NF-KB and MMP3}

The present results showed that the gene expression of inflammatory mediators and tissue repair factor, TFF3 levels produced a significant $(P<0.01)$ increase in DSS-induced ulcerative colitis when compared to control animals. Also, TFF3 was significantly $(P<0.01)$ reduced in the sulfasalazine group relative to the DSS treated group (fig. 1).

Table 3: Effect of oral administration of sulfasalazine on serum leucine-rich alpha-2-glycoprotein (LRG) as well as colon cyclic AMP, MPO and TNF- $\alpha$ in DSS induced ulcerative colitis in rats

\begin{tabular}{|c|c|c|c|c|c|}
\hline No. & Groups & $\begin{array}{l}\text { Serum } \\
\text { LRG (ng/ml) }\end{array}$ & $\begin{array}{l}\text { Colon cAMP (pmole } / \mathrm{mg} \\
\text { protein) }\end{array}$ & $\begin{array}{l}\text { Colon } \\
\text { MPO (U/mg) }\end{array}$ & $\begin{array}{l}\text { Colon TNF- } \alpha \\
\text { (ng/mg protein) }\end{array}$ \\
\hline \multirow[t]{2}{*}{ (I) } & Normal & 28.95 & 28.01 & 6.69 & 48.11 \\
\hline & (drinking water) & $\pm 3.07^{\mathrm{a}}$ & $\pm 3.90^{\mathrm{a}}$ & $\pm 0.93^{\mathrm{a}}$ & $\pm 4.66^{\mathrm{a}}$ \\
\hline \multirow[t]{2}{*}{ (II) } & Control positive & 87.18 & 12.56 & 16.97 & 300.61 \\
\hline & DSS (5\% in drinking water) & $\pm 7.52^{\mathrm{b}}$ & $\pm 1.44^{\mathrm{b}}$ & $\pm 1.55^{\mathrm{b}}$ & $\pm 7.43^{\mathrm{b}}$ \\
\hline \multirow[t]{2}{*}{ (III) } & DSS $(5 \%$ in drinking & 58.79 & 14.57 & 12.81 & 222.61 \\
\hline & water)+Sulfasalazine ( $500 \mathrm{mg} / \mathrm{kg}$. bw) & $\pm 5.76^{\mathrm{c}}$ & $\pm 1.57 \mathrm{c}$ & $\pm 0.97 \mathrm{c}$ & $\pm 5.09 \mathrm{c}$ \\
\hline
\end{tabular}

Data shown are mean \pm standard deviation of the number of results within each therapy, Data followed by the same letter are not significantly different at $\mathrm{P} \leq 0.05$.

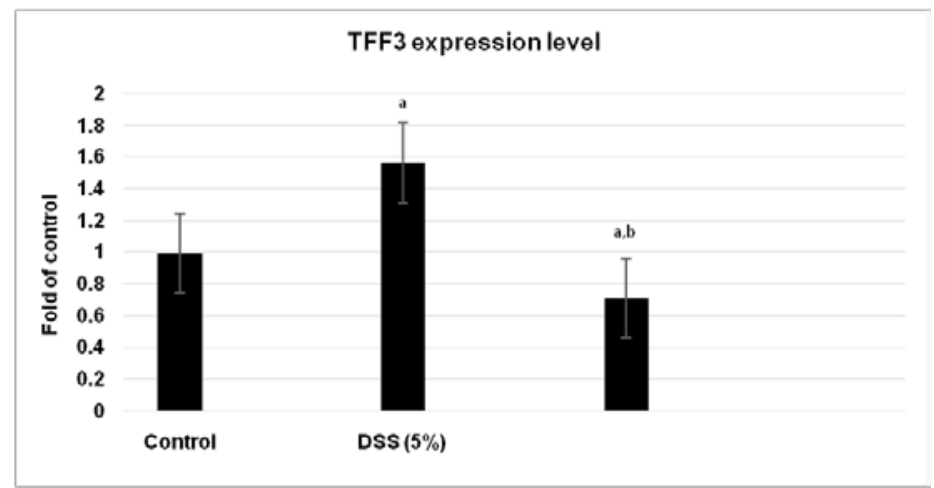

Fig. 1: Effect of sulfasalazine on serum trefoil factor 3 (TFF3) in the different studied groups of rats. Representative bar diagram of three independent experiments are presented

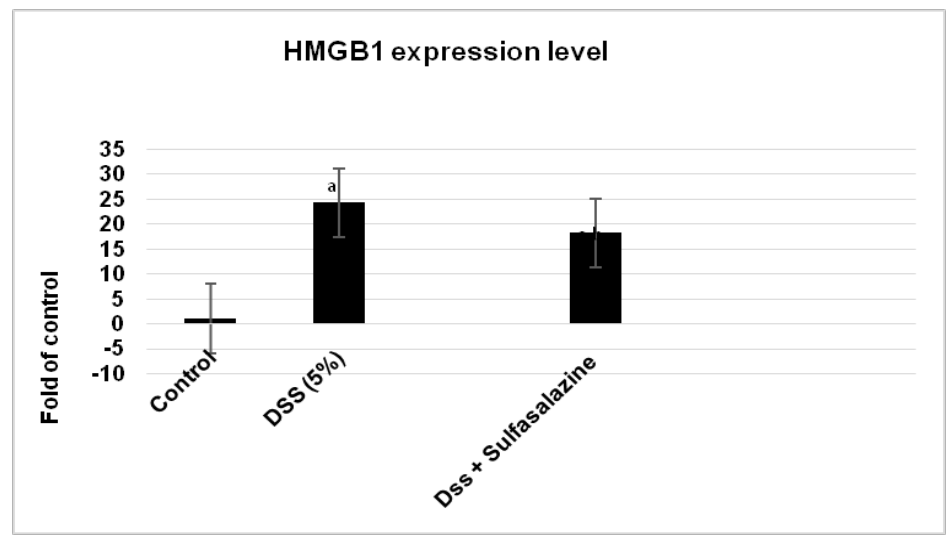

Fig. 2: Effect of sulfasalazine on serum high mobility group box-1 (HMGB1) in different studied groups of rats. Representative bar diagram of three independent experiments are presented 
The results are expressed as fold increase or decrease considering the control one. Significance was done at $p<0.05$. a: significant versus control b: significant versus DSS (sample size is 8 rats in each group)

The expression levels of serum HMGB1, nuclear factor- $\kappa \mathrm{B}(\mathrm{NF}-\kappa \mathrm{B}$ and MMP3 in the DSS group were higher than those in the control group $(\mathrm{P}<0.01)$. Sulfasalazine treatment significantly reduced the expression levels of HMGB1, NF- $\mathrm{B}$ and MMP3 $(\mathrm{P}<0.05)$ as compared with the DSS group (fig. 2,3,4,5).

The results are expressed as fold increase or decrease considering the control one. Significance was done at $p<0.05$. a: significant versus control, b: significant versus DSS (sample size is 8 rats in each group)

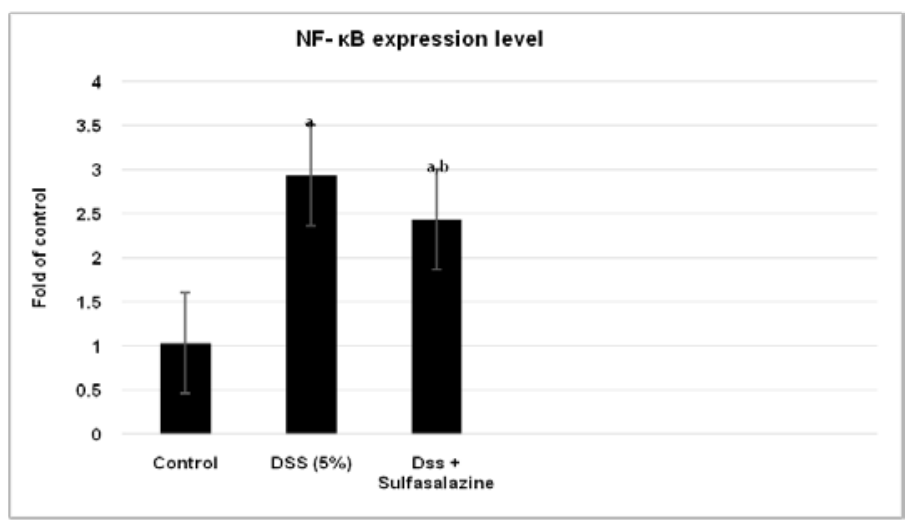

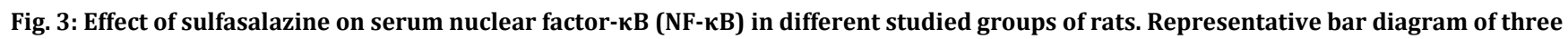
independent experiments are presented

The results are expressed as fold increase or decrease considering the control one. Significance was done at $\mathrm{p}<0.05$. a: significant versus control, b: significant versus DSS (sample size is 8 rats in each group)

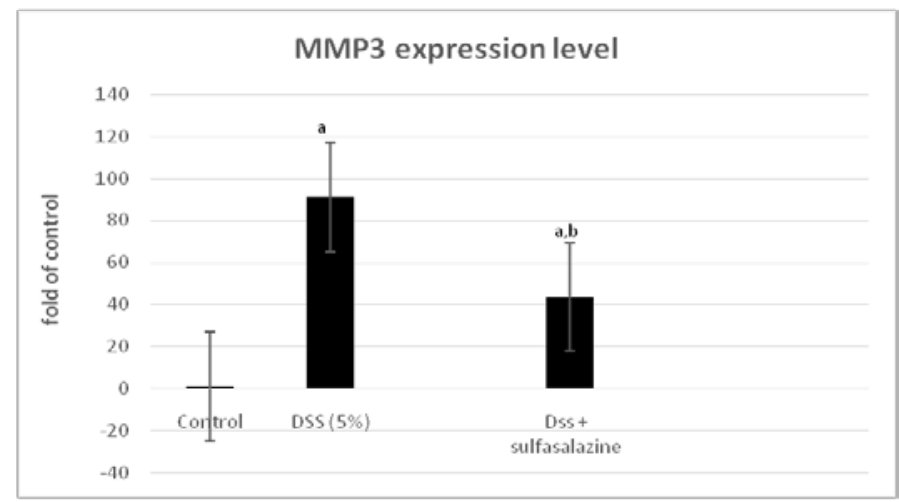

Fig. 4: Effect of sulfasalazine on serum matrix metalloproteinase 3 (MMP 3) in the different studied groups of rats. Representative bar diagram of three independent experiments are presented

The results are expressed as fold increase or decrease considering the control one. Significance was done at $\mathrm{p}<0.05$. a: significant versus control, b: significant versus DSS (sample size is 8 rats in each group)

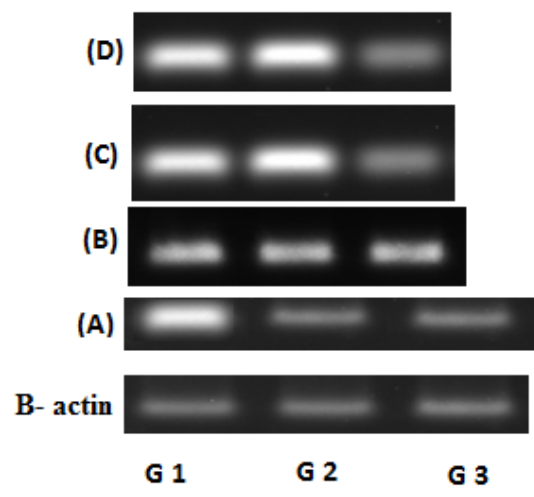

Fig. 5: An agarose gel electrophoresis shows PCR products of serum trefoil factor 3 (TFF3) (A), high mobility group box-1 (HMGB1) (B), nuclear factor- $\mathrm{KB}$ (NF- $\mathrm{\kappa B}$ ) (C), matrix metalloproteinase 3 (MMP 3) (D) and Beta actin in different studied groups as G1 stands for group I, G2 stands for group II and G3 stands for group III (sample size is 8 rats for each group) 


\section{Genetic expression level of miRNA-31 in colon}

The expression level of miRNA-31 was upregulated in colonic tissues treated with DSS by 3.3 times, compared to the normal group ( $\mathrm{P}<0.01$ ) (fig. 6). On the other hand, miRNA-31 expression level in sulfasalazine treated rat groups showed significant $(\mathrm{p}<0.05)$ down-regulation by $27 \%$ compared to the DSS colitis group.

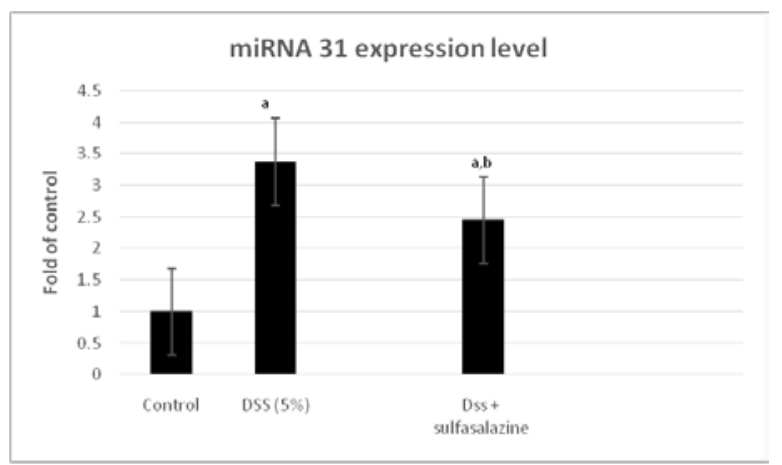

Fig. 6: Effect of sulfasalazine on colon miRNA 31 in the different studied groups of rats. Representative bar diagram of three independent experiments are presented

The results are expressed as fold increase or decrease considering the control one. Significance was done at $\mathrm{p}<0.05$. a: significant versus control, b: significant versus DSS (sample size is 8 rats in each group)

\section{Histopathological changes}

Colonic sections from control group revealed typical architecture of colon tissue (fig. 7 a).

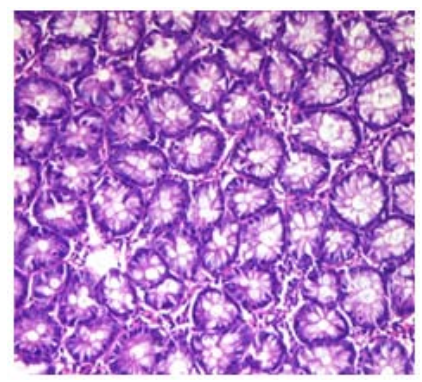

a) Normal Control: Normal architecture of the mucosa $(x 40)$

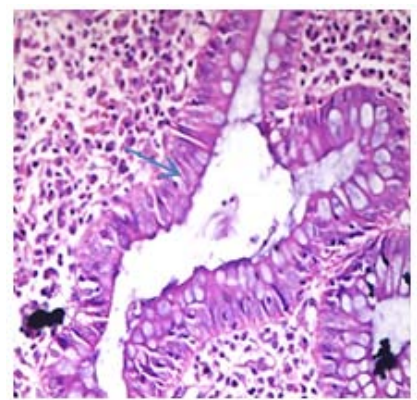

b) DSS colitis rats: Gryptitis, crept branching and distortion (x100)

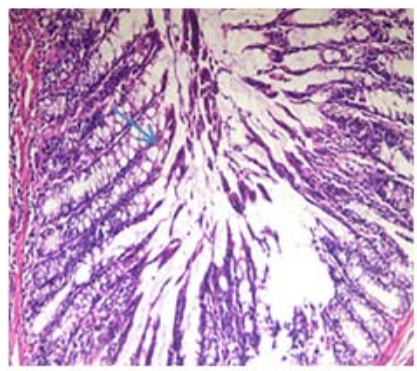

c) Sulfasalazine treated group: Normal mucosa and mild glandular reparative changes $(\mathrm{x} 40)$

Fig. 7: Photomicrographs of colon tissue sections (H and E)
On the other hand, Colons of the DSS group indicated ulceration with inflammatory cell infiltration (fig. 7 b) However, colons of the sulfasalazine treated group displayed nearly normal histological structure (fig. 7 c)

\section{DISCUSSION}

Inflammatory Bowel Disease (IBD) is a gastrointestinal tract, chronic inflammatory condition. IBD has historically been classified into Crohn's disease (CD) and ulcerative colitis (UC) [16]. Crohn's disease and Ulcerative Colitis are distinguished by their clinical manifestations and pathogenic mechanisms they hypothesize [17]. UC is a relapsing chronic inflammatory condition that is confined to the colon and marked by bloody diarrhea during disease flares [18]. The $\mathrm{CD}$ is a chronic, segmental localized granulomatous disease that can affect from the mouth to the anus anywhere in the entire gastrointestinal tract. Ulcerative Colitis and Crohn's disease can occur at any age, yet most patients are diagnosed during their third decade of life [18].

The present study verified the comparative evaluation of sulfasalazine's pharmacological efficacy in the rat model of UC. As shown in fig. 7 DSS group demonstrated inflammatory cell infiltration edema and lining mucosal epithelium desquamation. These findings may be due to the direct lethal effect of DSS resulting in breakdown of the mucosal epithelial barrier. Our findings were in line with other earlier reports [19]. Treatment with sulfasalazine ameliorated histopathological changes. As shown in table 1, the DSS control group displayed significantly reduced cAMP and increased LRG, MPO and TNF- $\alpha$ as compared with the normal group. Results from previous studies showed that the level of MPO and TNF- $\alpha$ was increased with the seriousness of experimental colitis [20-21].

Administration of sulfasalazine caused anti-inflammatory effects, including decreased serum LRG, MPO and TNF- $\alpha$ levels, among the DSS-treated groups. The present results were confirmed by the results of Mi et al. [9].

Previous studies suggested the significance of oxidative stress caused by reactive oxygen species (ROS) in the development of UC [20, 22]. In addition, NADPH oxidase enzymes, including NADPH oxidase 4 (NOX4), neutrophil cytosol factor 1 (p47 phox), and Rac related c3 botulinum toxin substrate 1 (Rac1) are the main producers of ROS $[23,24]$. ROS Overproduction via NADPH oxidase has been implicated in tissue damage observed in chronic inflammatory disorders [25] and plays critical roles in diverse biological processes, including host defense, cell growth and differentiation, proinflammatory genes activation, and cell death [26]. In the current research, the DSS injury was vastly higher than in the normal group, whereas sulfasalazine treatment significantly reduced the damage by DSS [9]. 
Serum TFF3 was substantially increased in patients compared to healthy volunteers. Serum TFF3 levels were also significantly higher in patients who had no mucosal healing than in those with mucosal healing. These findings emphasize the hypothesis that TFF3 levels are correlated with intestinal mucosal inflammation and increased with the mucosal damage presence [27]. Grønbaek et al. [28] found that serum TFF3 levels were correlated with disease activity indices in patients with UC and they noted a potential to decrease TFF-3 levels with clinical improvement steroids therapy and these results support our study. In the research conducted by Grønbaek et al. [28], there were significant variations in quantitative peptide measurements among individuals, which the authors felt was a pitfall of using trefoil peptides as a biomarker.

It is found that Sulfasalazine has a remarkable effect on decreasing DSS-induced secretion of proinflammatory cytokines in rats with colitis, in order to suppress inflammatory responses in intestinal epithelial cells. From our findings, it can be concluded that mRNA levels of HMGB1, NF- $\kappa$ B and MMP 3 as well as miRNA-31 in rats with DSS-induced colitis are increased, while those are reduced by oral administration of sulfasalazine. Consequently, sulfasalazine contributes to the reduction of proinflammatory cytokines levels. Additionally, NF- $\kappa \mathrm{B}$ is known to be an important factor for activation of IBD in humans and colitis in animals [29]. Antisense oligonucleotides can actually inhibit disease activity in rats with colitis, suggesting that NF- $\kappa \mathrm{B}$ plays an essential role in inflammatory response mediation [30].

The results of our current research showed that relative to rats in the control group, the expression of HMGB1, NF- $\mathrm{B}$, TFF3 and MMP 3 as well as miRNA-31 were increased. Recent findings have found the significant roles of miRNAs in immune regulation, especially their potential utility as a novel anti-inflammatory agent to treat inflammatory diseases $[31,32]$. In the acute colitis model, mucosal inflammation can be managed by using an agent to block the pathway of $N F-\kappa B$, which marks a positive attempt [33]. Similar experimental outcomes can also be obtained, which are that sulfasalazine treatment can block phosphorylation of IкB and nuclear translocation of NF- $\kappa \mathrm{B}$, indicating that sulfasalazine inhibits the NF- $\kappa$ B signal pathway [33].

\section{CONCLUSION}

Our study suggested that prior and concomitant administration of Sulfasalazine ahead of DSS significantly improved morphological, biochemical and histological features of ulcerative colitis. The antiinflammatory action of Sulfasalazine is due to the decrease of inflammatory mediators TNF- $\alpha$, MPO and LRG and down regulation of HMGB1, NF-KB, MMB3, TFF3 and miRNA31 genes and increase of anti-inflammatory molecule cAMP. Further studies are warranted to identify other molecular mechanisms concerning Sulfasalazine.

\section{ACKNOWLEDGMENT}

The author gratefully acknowledges Prof. Dr. Amal Haridy for her conducting and interpreting the histopathological investigations.

\section{COMPLIANCE WITH ETHICAL STANDARDS}

All procedures performed in this study involving animals were in accordance with ethical guidelines established by animal care.

\section{FUNDING}

Nil

\section{AUTHOR CONTRIBUTION}

SA conceived, designed research, conducted experiments, contributed reagents, analyzed data and wrote the manuscript. The author read and approved the manuscript and all data was generated in-house and that no paper mill was used.

\section{CONFLICT OF INTERESTS}

No conflicts of interests were declared by the author and this study is not funded by the institution.

\section{REFERENCES}

1. Gearry RB. IBD and environment are there differences between east and west. Dig Dis 2016;34:84-9.

2. Mshimesh B. Efficacy and safety of adalimumab versus infliximab in patients suffered from moderate to severe active ulcerative colitis. Asian J Pharm Clin Res 2017;10:300-7.

3. Monteleone G, Biancone L, Marasco R, Morrone O, Marasco O, Luzza F, et al. Interleukin 12 is expressed and actively released by Crohn's disease intestinal lamina propria mononuclear cells. Gastroenterology 1997;112:1169-78.

4. Okayasu I, Hatakeyama S, Yamada M, Ohkusa T, Inagaki Y, Nakaya R. A novel method in the induction of reliable experimental acute and chronic ulcerative colitis in mice. Gastroenterology 1990;98:694-702.

5. Thakur V, Singh B, Sharma A, Kumari N, Kumar I, Verma K, et al. Importance of nanocarriers and probiotics in the treatment of ulcerative colitis. Int J Appl Pharm 2021;13:77-85.

6. Mattam J, Sailaja K. Preparation and evaluation of sulfasalazine loaded sodium alginate microbeads for sustained delivery. Asian J Pharm Clin Res 2016;9:66-70.

7. Desreumaux P, Ghosh S. Review article: mode of action and delivery of 5-aminosalicylic acid-new evidence. Aliment Pharmacol Ther 2006;24:2-9.

8. Benoit C, Jesse D, Madhu M, Matam V. Dextran sulfate sodium (DSS)-induced colitis in mice. Curr Protoc Immunol 2014;25:1-15.

9. Mi R, Kyeong J, Soo H, Su J, Bu I, Hyo J, et al. Comparative evaluation between sulfasalazine alone and in combination with herbal medicine on DSS-induced ulcerative colitis mice. BioMed Res Int 2017;3:1-10.

10. Arab HH, Al-Shorbagy MY, Abdallah DM, Nassar NN. Telmisartan attenuates colon inflammation, oxidative perturbations and apoptosis in a rat model of experimental inflammatory bowel disease. Plos One 2014;9:e97193.

11. Kawakami M, Kaneko N, Anada H. Measurement of interleukin-6, interleukin-10, and tumor necrosis factor-alpha levels in tissues and plasma after thermal injury in mice. Surgery 1997;121:440.

12. El-Ashmawy N, Khedr N, El-Bahrawy H, El-Adawy S. Roflumilast, type 4 phosphodiesterase inhibitor, attenuates inflammation in rats with ulcerative colitis via down-regulation of iNOS and elevation of cAMP. Int Immunopharmacol 1997;56:36-42.

13. Krawisz J, Sharon P, Stenson W. Quantitative assay for acute intestinal inflammation based on myeloperoxidase activity: assessment of inflammation in rat and hamster models. Gastroenterology 1984;87:1344-50.

14. Lowry O, Rosebrough N, Farr A, Randall R. Protein measurement with the folin phenol reagent. J Biol Chem 1951;193:265-75.

15. Chen C, Ridzon DA, Broomer AJ, Zhou Z, Lee DH, Nguyen JT, et al. Real-time quantification of microRNAs by stem-loop RTPCR. Nucleic Acids Res 2005;33:e179.

16. Baumgart DC, Sandborn WJ. Inflammatory bowel disease: clinical aspects and established and evolving therapies. Lancet 2007;369:1641-57.

17. Gaya DR, Russell RK, Nimmo ER, Satsangi J. New genes in inflammatory bowel disease: lessons for complex diseases? Lancet 2006;367:1271-84.

18. Strober W, Murray PJ, Kitani A, Watanabe T. Signalling pathways and molecular interactions of NOD1 and NOD2. Nat Rev Immunol 2006;6:9-20.

19. Zhang ZL, Fan HY, Yang MY, Zhang ZK, Liu K. Therapeutic effect of a hydronaphthoquinone fraction on dextran sulfate sodium-induced ulcerative colitis. World J Gastroenterol 2014;20:15310-8.

20. Rogler G. Gastrointestinal and liver adverse effects of drugs used for treating IBD, best practice and research. Clin Gastroenterol 2010;24:157-65.

21. Buchheister S, Buettner M, Basic M. CD14 plays a protective role in experimental inflammatory bowel disease by enhancing intestinal barrier function. Am J Pathol 2017;187:1106-20.

22. Macfarlane S, Steed H, Macfarlane GT. Intestinal bacteria and inflammatory bowel disease. Crit Rev Clin Lab Sci 2009;46:25-54.

23. Kotlowski R, Bernstein CN, Sepehri S, Krause DO. High prevalence of Escherichia coli belonging to the $\mathrm{B} 2+\mathrm{D}$ 
phylogenetic group in inflammatory bowel disease. Gut 2007;56:669-75.

24. Braun A, Treede I, Gotthardt D, Tietje A, Zahn A, Ruhwald R Alterations of phospholipid concentration and species composition of the intestinal mucus barrier in ulcerative colitis: a clue to pathogenesis. Inflamm Bowel Dis 2009;15:1705-20.

25. Rahimi R, Nikfar S, Rezaie A, Abdollahi MA. Meta-analysis of broad-spectrum antibiotic therapy in patients with active Crohn's disease. Clin Ther 2006;28:1983-8.

26. Hoffmann W. Trefoil factors TFF (trefoil factor family) peptidetriggered signals promoting mucosal restitution. Cell Mol Life Sci 2005;62:2932-8.

27. Srivastava S, Kedia S, Kumar S, Mouli VP, Dhingra R, Sachdev $\mathrm{V}$, et al. Serum human trefoil factor 3 is a biomarker for mucosal healing in ulcerative colitis patients with minimal disease activity. J Crohn's Colitis 2015;9:575-9.

28. Grønbaek H, Vestergaard EM, Hey H, Nielsen JN, Nexo E. Serum trefoil factors in patients with inflammatory bowel disease. Digestion 2006;74:33-9.
29. Wang KP, Zhang C, Zhang SG, Liu ED, Dong L, Kong XZ, et al. 3(3-pyridylmethylidene)-2-indolinone reduces the severity of colonic injury in a murine model of experimental colitis. Oxid Med Cell Longev 2015. https://doi.org/10.1155/2015/959253

30. Islam MS, Murata T, Fujisawa M, Nagasaka R, Ushio H, Bari AM, et al. Anti-inflammatory effects of phytosteryl ferulates in colitis induced by dextran sulfate sodium in mice. $\mathrm{Br} J$ Pharmacol 2008;154:812-24.

31. Tahamtan A, Teymoori Rad M, Nakstad B, Salimi V. Antiinflammatory microRNAs and their potential for inflammatory diseases treatment. Front Immunol 2018;9:1377.

32. Sylvia A. Boshra resveratrol modulates miR-34a in cardiotoxicity induced by isoproterenol. J Med Food 2020; 23:593-9.

33. Zheng L, Zhang YL, Dai YC, Chen X, Chen DL, Dai YT, et al. Jianpi qingchang decoction alleviates ulcerative colitis by inhibiting nuclear factor- $\kappa \mathrm{B}$ activation. World J Gastroenterol $2017 ; 23: 1180-8$ 